\title{
A PHYSIOTHERAPY PROGRAMME FOR THE TOTAL HIP REPLACEMENT
}

By

\author{
A. I. LIFSCHITZ, \\ B.Sc. (Physiotherapy) Witwatersrand
}

It may be said that "what the quadriceps ale to the knee. the abductors are to the hip'.

This is especially true in the rehabilitation of the Total Hip Replacement, e.g. the Charnley arthroplasty, and therefore it is important to understand the function of the hip abductors particularly, i.e. abduction of the mobile pelvis on a fixed femur; and (prevention of adduction of the pulvis on the weight-bearing hip).

In the Charnley arthroplasty. the detachment and reattachment of the greater trochanter more inferiorly is done in order to achieve an increased mechanical advantage of the abductors.

The physiotherapy management followed at the Workmen's Rehabilitation Hospital consists of four main phases:

A. Pre-Operative Stage.

B. Post-Operative Stage, including:
1. Bed Rest Stage
2. Pre-Ambulatory Stage
3. Ambulatory Stage.

\section{A. Pre-Operative Stage:}

Pre-operative treatment is important for a numbel of reasons:

1. To find out the history of the patient.

2. To assess the patient initially. This should include functional ability; use, type and number of walking aids: distance capable of walking: type of gait pattern, lumbar spine, hip, knee and ankle joint rangc. muscle strength about the hip and knee. In particular patients will be examined for positive Trendelenberg sign and fixed flexion deformity of the hip (which will be corrected routinely during operation if present).

3. To gain the full co-operation of the paticnt so rehabilitation will be faster and more effective by educating him/her as to the operation and planned physiotherapy programme.

\section{B. Post-Operalive Stage:}

1. Bed Rest Stage: this lasts l'or approximately 4 days.

Immediately post-operatively. the patient lies supine with his/her head supported by one pillow, and a trapezoidal Charnley abduction pillow (see Fig. 1), between the legs, from knees to ankles. This has the advantage of maintaining $15^{\circ}$ of hip abduction (to prevent any strain on the greater trochanter) and it is maintained foc a week or two.

The bed is elevated initially to aid venous return and the patient has an intravenous antibiotic drip. 1-2 portovac drains from the hip and occasionally a cottonwool spica, remaining on for 48 hours.
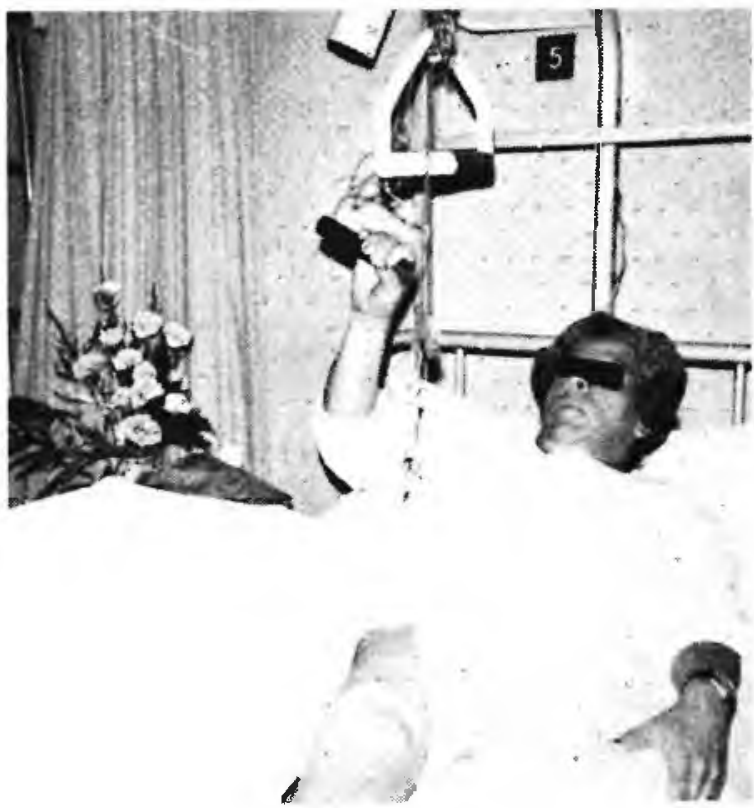

Fig. 1: Apparatus for the Chamley Exercise Programme.

Note: The Charnley Pillow in situ and the locker on the opposite side to the affected limb.

\section{Aims of Ireatment:}

(a) To maintain the circulation and to prevent the formation of deep vein thrombosis.

(b) To prevent any chest complications

\section{Programme:}

1. Deep breathing (diaphragmatic and lateral costal) with coughing.

2. Strong ankle dorsi- and plantar flexion.

3. Static contractions are given to the quadriceps and hip extensors, but not to the hip abductors.

This is repeated 4 times per day for 4 days.

Points to note:

(a) It is important to help prevent pressure sores which tend to occur on the heels.

(b) The tendency for the patient to lie with the hips in external rotation. This is due to gravity and weakness of the internal rotators and may be prevented by getting the patient to rotate the whole body till feet are in the neutral position, then relaxing the body to neutral position. Alternativelly sandbags may be used to prevent this. 
(c) The physiotherapist must instruct the patient. in avoiding possible positions of dislocation, i.e.

(i) The hip must not be flexed beyond $45^{\circ}$, adducted across the midline or internally rotated.

(ii) The patient is warned not to. cross the legs, or

(iii) to force adduction by turning into side lying unsupervised.

(iv) The lockers should be placed on the unoperated side of the patient. If the patient should be reaching for this item the operated limb will tend to stay in a relative position of abduction with relationship to the pelvis. (See Fig. 1).

2. Pre-Ambulatory Stage: This stage usually commences between the 5th and 6th day but may vary depending entirely on the individual's state of fitness. This stage must not be pushed.

\section{Aims of treatment:}

(a) To get the patient out of bed standing (usually partially weight-bearing) with legs in abduction (weight-bearing itself is considered an exercise).

(b) To allow balance reactions to readjust.

The patient gets out of bed with the assistance of an overhead 'monkey chain', and the opposite leg first moving towards the side of the bed. Here one can allow up to $45^{\circ}$ of hip flexion but the leg must remain in the inner range of abduction and external rotation is also avoided. The patient's operated leg should be fully supported by the physiotherapist in the early stages. The patient stands for a few minutes with the hips abducted holding onto the back of a chair. At this stage the patient may be measured for crutches, or previously taken measurements checked.

In getting back to bed the leg is again supported in abduction and less than $45^{\circ}$ of flexion and patient uses the chair, opposite leg and overhead monkey chain to assist the manoeuvre.

At this stage (5th to 6th day) active sling exercises in the pain-free range may be commenced, emphasis being on the functional aspects of range. These. sling exercises are carried out on a modified Guthrie Smith suspension system with the Chanley abduction pillow still placed between the legs. (Sec. Fig. 1).

\section{Exercises:}

1. Patient does assisted-active hip flexion with passive knee flexion.

2. Patient does assisted-active hip flexion with knee extension.

3. Patient does resisted hip extension with manual resistance through the handle. This may be called auto resisted hip extension.

The above are done one after the other in sequence.

4. Patient does exercise 2, then moves leg into abduction with internal rotation as far as possible. The other leg must be stabilized in extension and abduction to prevent pelvis from moving. This may be called assisted-active hip abduction.

The exercises are done on a 10 repetition basis where possible.

3. Ambulatory Stage: This stage usually begins on the 7 th or 8 th day post operatively.

Aims of treatment: to teach the patient the correct gait pattern.
The patient starts walking as soon as he/she has good abductor control, is stable on his/her feet with normal balance. Axillary crutches are used and a three noint gait is taught.

The importance of normal walking style is stressed. A long mirror is often found useful to eliminate any bad postural habits and faults in gait.

\section{Common Faults in Gait:}

1. Stiff knee gait. The patient tends to rotate pelvis rather than flex the hip through.

2. A tendency to heel-raise on the opposite leg to compensate for stiffness in hip flexion of operated limb.

3. External rotation: As the patient is in the 'push off' stage the Charnley leg goes into external rotation.

4. Patients with bilateral hip arthroplasty of ten have stiffness in hip flexion and therefore compensate by decreasing the lumbar lordoses thus appearing to gain more hip flexion.

5. Uneven steps: usually the unoperated leg is brought through quickly.

6. Patient should flex the knee in front of them.

7. Climbing stairs the patient tends to heel-raise on opposite leg in order to compensate for lack of hip flexion in Charnley limb.

Some patients such as those with rheumatoid arthritis, having several joints involved, benefit both physically and psychologically from pool therapy.

This may be begun only 24 hours after the sutures have been removed (this is usually between 12 th and 14th day).

The patients are encouraged to take as much weight on the hip as possible.

Patients often experience pain in the knee for the first week after operation and this is attributed to various manoeuvres done during operation.

Sitting: This commences as an activity on the 10th day ONLY as slope-sitting.

Exercises in sitting such as static contractions of glutei, quadriceps and foot dorsi- and plantar flexion are given.

Before discharge the patient is taught to climb stair slopes and practise is given in turning. The patient is also taught how to lie in side lying with pillows between the legs to maintain hip abduction.

The patient may also be given general maintenance exercise in a simple home programme and is usually discharged in 2-3 weeks. Patients are instructed about avoiding various positions of dislocation, to sleep on a firm mattress and to walk daily.

They may play such sports as bowls, golf, swimming but exercises involving jarring movements such as running are advised against.

\section{Average Level of Function at Discharge.}

The hip musculature can be generally graded a 3 and the patient does not have full hip flexion. This allows him/her to sit in a high chair, but not to do up his shoe laces.

In general the patient will remain on two crutches until the end of six weeks post-operatively, one crutch at the end of eight weeks, then a cane.

They are often free of ambulatory aids by the end of three months post-operatively. 


\section{Note on the Charnley-Muller arthroplasty}

Like the Charnley arthroplasty, this is also a metal on plastic articulation but has a larger femoral head on plastic available in three different neck lengths. It does not necessitate the transfer of the greater trochanter.

The aim of the design was to provide $110^{\circ}$ of motion (as opposed to about $90^{\circ}$ in the Charnley arthroplasty) without subluxation because this range of motion in excess of $90^{\circ}$ is very important in many activities of daily living.

\section{Post-Operative Management:}

This is much the same as the Charnley arthroplasty but the periods are much shorter. The patient may be walking as soon as 48 hours post-operatively, and rehabilitation is generally much more rapid.

\section{Summary}

The striking feature of this operation is that the patient is subjected to very little or no post-operative stress, in contrast to the rigorous rehabilitation demanded after partial hip replacement such as cup arthroplasty. Provided there is no mechanical mishap or infection, pain vanishes, and because there is no reflex inhibition, movement of the new joint is easily regained.

1t is also unquestionable that the procedure of total hip replacement demands a high standard of teamwork among the members of the Unit, and successful outcome is dependent on this factor.

\section{Opsoming}

Die opvallende kenmerk van hierdie operasie is dat die pasiënt na die operasie aan min of geen kommer blootgestel is nie. Dit is in teenstelling met die drastiese rehabilitasie wat verwag word na gedeeltelike heup vervanging soos 'cup arthroplasty' Mits daar geen meganiese terugslag of infeksie is nie, sal die pyn verdwyn en aangesien daar geen refleksbeperking is nie sall die beweging van die nuwe gewrig maklik herstel.

Dit is ongetwyfeld dat algehele heup vervanging 'n hoë samewerking onder die lede van die Eenheid vereis en die sukses van die operasie hang af van hierdie spanwerk.

\section{Acknowledgements}

Professor L. Solomon and his Unit at Workmen's Rehabilitation Hospital.

\section{LETTERS TO THE EDITOR}

\author{
Forest Town School for Cerebral Palsied Children. \\ 15th July, 1974.
}

The Editor,

Journal,

South African Society of Physiotherapy,

P.O. Box 11151 ,

Johannesburg.

\section{Dear Madam,}

A comment on the article "A short reappraisal of ahe Principles of treatment in Cerebral Palsy" by Miss S. Irwin-Carruthers in Physiotherapy May 1974, seems called for to elucidate certain points that may possibly be misleading.

Firstly, may I acknowledge the article as a valuable summary of the neurodevelopmental approach, which should be useful to all students and therapists who are working in this field. That this approach is basic in the treatment of cerebral palsy is now generally accepted. (That is why acquisition of knowledge of this approach is a prerequisite in this Department and eight of the eleven therapists are fully Bobath trained). Unfortunately, the approach falls into disrepute when its disciples fail to keep up with its originators, who declare that they take the ideas of Peto, Voijta, PNF, absorb them, make them their own and use them, also claiming eclecticism (Personal communication 1972). This is why the originator of the approach remains the greatest therapist in the world in the treatment of cerebral palsy.

It cannot, however, be stressed enough that an eclectic approach can only be successfully employed by therapists with a thorough understanding of normal development (Peiper 1936) and the disturbances of motor function in cerebrall palsy (as far as present knowledge allows) (Bobath 1972) as well as of the different treatment methods. It is therefore safer for undergraduates or inexperienced therapists to stick to one approach, even though the end result of treatment may not be as good as it would have been had different methods been used to deal with the multifarious problems which arise in cerebral palsy.

It is also necessary to recognise that different methods of treatment have evolved, using the same sound neurophysiological principles on which the neurodevelopmental approach is based. One cannot ignore the work of Kabat and Knott, Rood, Brunnstrom and Voijta. In addition, as a caution, the oft quoted thought "neurophysiclogic" doctrine is a most perishable commodity and it is a mistake to pin one's hopes on a current interpretation" (Mead 68).

As far as planning treatment is concerned, do we really want to retain primitive patterns by utilising them early in treatment (as does Brunnstrom) or do we want to inhibit their effect and facilitate secondary responses? I think that here misunderstanding may be merely a matter of semantics. The argument against surgery and bracing admirably describes the difficulties which may arise and be perpetuated when conditions for using surgery in cerebral palsy are not favourable. lt is absolutely necessary to have a unit where the surgeon is not only conversant with the neurological condition of the child who has secondary orthopaedic problems (Samilson 66) but who is also prepared to work with the therapists (Holt 66), thereby ensuring that the patient is wholly controlled and all treatment integrated.

Most of the unfavourable changes should be avoided or overcome, but it should be pointed out that certain others, e.g. circulatory problems, are a primary symptom in cerebral palsy (Ingram 73) as are sensory disturbances. These may in fact be improved by the increased mobility produced by surgery.

As far as the shunting of spasticity is concerned, more recent studies have shown that even simple tendon release often results in unexpected improvement in a tone in a whole extremity as well as the homologous limb. (Nathan and Dmitrijevic 1967). This has been one empirical observation also. 